\title{
Does the Mediterranean Sea Influence the European Summer Climate? The Anomalous Summer 2003 as a Test Bed
}

\author{
LORENZO TOMASSINI AND ALBERTO EliZALDE \\ Max Planck Institute for Meteorology, Hamburg, Germany
}

(Manuscript received 12 June 2011, in final form 4 May 2012)

\begin{abstract}
The European summer 2003 presents a rare opportunity to investigate dynamical interactions in the otherwise variable European climate. Not only did air temperature show a distinct signal, but the Mediterranean sea surface temperature (SST) was also exceptionally warm.

The traditional view of the role of the Mediterranean Sea in the climate system highlights the influence of the atmospheric circulation on the Mediterranean Sea. The question of whether the Mediterranean Sea feeds back on the atmospheric dynamics is of central importance.

The case of the extremely anomalous summer 2003 allows for investigating the issue under realistic boundary conditions. The present study takes advantage of a newly developed regional coupled atmosphereocean model for this purpose.

Experiments with prescribed historical versus climatological SST suggest that the local atmospheric circulation is not strongly sensitive to the state of the Mediterranean Sea, but its influence on the moisture balance and its role in the regional hydrological cycle is substantial. Warmer Mediterranean SSTs lead to enhanced evaporation and moisture transport in the atmosphere.

Results of regional coupled simulations with different ocean initial conditions imply that because of the strong stratification of the surface waters in summer, the response time of the upper layers of the Mediterranean Sea to atmospheric forcing is rather short. It can be concluded that the role of the Mediterranean Sea in the European summer climate is mostly passive. In winter, however, since the upper layers of the Mediterranean Sea are well mixed, the memory of the Mediterranean SSTs stretches over longer time scales, which implies a potential for actively governing regional climate characteristics to some extent.
\end{abstract}

\section{Introduction}

The atmospheric dynamics over Europe is characterized by high variability on a wide range of time scales. It is therefore difficult to identify signals in order to quantify specific interactions of different components of the regional climate system. The summer of 2003 represents such a signal and provides the rare opportunity to investigate the interrelation of certain variables under anomalous conditions.

It is not fully understood why the large-scale circulation during summer 2003 showed the observed structure (Black et al. 2004). The anomalous anticyclonic conditions over Europe were caused by a northward displacement of the subtropical Azores anticyclone, which

Corresponding author address: Lorenzo Tomassini, Max Planck Institute for Meteorology, Bundesstrasse 53, 20146 Hamburg, Germany.

E-mail: lorenzo.tomassini@zmaw.de extended from the mid-Atlantic through to eastern Europe. At the same time, the Icelandic low was farther south than normal. The streamfunction anomalies in the European Centre for Medium-Range Weather Forecasts (ECMWF) analysis show an alternating sign from South America to Europe and beyond, suggesting a Rossby wave signal propagating from tropical America. The intensification of the Azores anticyclone was accompanied by a regional northward shift and intensification in the West African ITCZ and a southward shift in the summer extratropical storm track (Black et al. 2004; Cassou and Terray 2005).

Even though the situation of summer 2003 matched certain features of European atmospheric summer variability, the dimension of the event was unusual. One could hypothesize that a possible reason for the extent of the extraordinary conditions was an amplification by an anomalous state of the surrounding oceans (Feudale and Shukla 2011a). The Mediterranean sea surface temperatures built up quickly at the end of April and beginning 
of May 2003 (Grazzini and Viterbo 2003). They grew further in May and rapidly became very large in the first week of June. The area covered by the anomaly expanded and at the end of July affected almost the whole basin with the Aegean Sea as an exception. Subsequently Mediterranean sea surface temperatures persistently exceeded climatological values by $2^{\circ}$ to $3^{\circ} \mathrm{C}$.

Although it is clear that atmospheric dynamical conditions played an important role in the development of the European summer of 2003, the question arises as to in what way and to what extent the anomalous Mediterranean SSTs acted back on the atmosphere. The fact that the event had a large-scale characteristic that was not confined to the Mediterranean Sea lead Xoplaki et al. (2003) to the conclusion that the Mediterranean Sea was a passive element in the system. Similarly, since in contrast to the banded pattern of Atlantic radiative flux anomalies, the Mediterranean SST signature amplified most rapidly between May and June and hardly changed between July and August, Black et al. (2004) suggested that SST anomalies responded passively to radiative flux anomalies.

On the other hand, Black and Sutton (2007) show that an ensemble of global atmosphere model simulations forced by the observed summer 2003 sea surface temperatures reproduces the atmospheric conditions in the mean, although the anomaly over Europe is considerably weaker in their setup. An experiment with Mediterranean sea surface temperatures set to climatological values suggests a significant influence of Mediterranean SSTs on the atmosphere when compared to the historical control integration for summer 2003. Similarly, Feudale and Shukla (2007) achieved a simulation of the summer 2003 heat wave to a certain extent by forcing a global atmospheric general circulation model with observed sea surface temperatures [see also Feudale and Shukla (2011b)]. An experiment with observed SST anomalies over the Mediterranean Sea reproduces the upper-level anticyclone over central Europe, although in a weaker form. The resulting temperature anomalies showed about half of the amplitude compared to the experiment with global SST anomalies prescribed.

Somewhat contrary to these results, Jung et al. (2006) concluded in a study based on comparable modeling experiments that the Mediterranean Sea plays a minor role, if any, in maintaining the anomalous atmospheric circulation as observed in the summer of 2003. In contrast, the perturbations of the humidity fields caused by the Mediterranean SST anomalies proved to be significant.

But even if the European summer climate is sensitive to Mediterranean sea surface temperatures, this does not answer the question of whether the role of the Mediterranean Sea is active or passive. The high Mediterranean
SSTs could have been merely a consequence of the warm temperature of the atmosphere. The question whether the Mediterranean Sea actively influences the European summer climate and in what ways can only be answered using a coupled atmosphere-ocean model. The issue is intimately connected with the question about the memory in the upper layers of the Mediterranean Sea. If the surface waters of the Mediterranean Sea do not remember their past state, this implies that they are driven by the atmosphere.

The aim of the present work is to explore the role of the Mediterranean Sea in the European summer climate. In particular, we investigate the possibility of an influence of the Mediterranean Sea on the atmospheric dynamics that would sustain a pressure anomaly as observed during summer 2003. Moreover, the effect of enhanced Mediterranean SSTs on the regional water cycle is examined. Employing a regional model allows for a controlled experimental setup that focuses on regional processes and guarantees, because of the realistic boundary forcing, that the characteristics of the summer 2003 are reproduced adequately. Various sensitivity experiments are performed within this framework using an atmosphere-only and a newly developed regional coupled ocean-atmosphere model for the Mediterranean area.

The summer 2003 is used as a test bed because the Mediterranean SST anomaly was particularly strong during this time, and because the westerly flow and the large-scale forcing by mesoscale eddies that usually dominate the weather conditions in Europe was weak. Such circumstances allow for a more discernible influence of regional factors such as the Mediterranean Sea on the atmospheric circulation.

The paper is structured as follows. Section 2 gives an overview of the climate model and the performed experiments. In section 3 the climate model is validated. Mainly simulated anomalies, and not the climate (which is tunable to some degree), are compared to observations. The first part of section 4 is devoted to the question whether the European summer climate is sensitive to Mediterranean SSTs. This is investigated using a regional atmospheric model and prescribed SSTs. But even if the answer to this question is affirmative, the Mediterranean Sea could be purely driven by the atmosphere. Therefore the second part of the section treats the central question of this study and examines the role and the memory of the Mediterranean Sea using the regional coupled atmosphere-ocean model. The discussion centers on the question whether the upper layers of the Mediterranean Sea are mainly governed by the atmosphere, or if the Mediterranean Sea plays an active role in shaping the European summer climate. A 


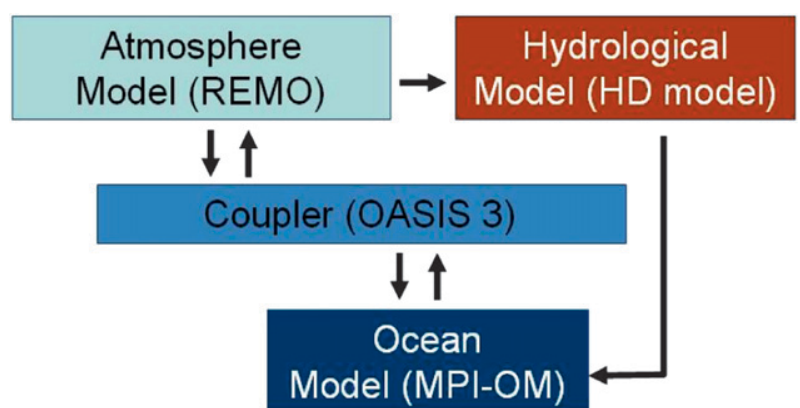

FIG. 1. Schematic of the regional coupled atmosphere-ocean model including a hydrological discharge model.

section containing the main conclusions completes the paper.

\section{Climate model and experiments}

\section{a. Climate model}

For the present study we use a recently developed regional coupled atmosphere-ocean climate model (Elizalde et al.2010) consisting of the regional atmosphere model REMO, a regional version of the Max Planck Institute for Meteorology global ocean model (MPI-OM), and the hydrological discharge (HD) model. The OASIS3 software (available online at https://verc.enes.org/models/ software-tools/oasis) couples the components. In the standard coupling configuration REMO calculates fluxes of heat, momentum, and freshwater for each grid box and receives in turn SST properties from the ocean model. The coupling is updated every $6 \mathrm{~h}$ for all variables except for the freshwater discharge, which is updated daily. Figure 1 shows a schematic of the coupled model.

REMO (Jacob 2001) is a three-dimensional, mesoscale atmospheric circulation model that solves the discretized primitive equations of atmospheric motion. It is based on the Europa-Modell of the German Weather Service. The physical parameterizations are taken from the global atmospheric model ECHAM-4. In the present study REMO is run at a resolution of $25 \mathrm{~km}$ with 31 vertical levels. As a limited area model, REMO needs lateral boundary forcing data for temperature, wind, surface pressure, and moisture. Over the sea, REMO relies on the sea surface temperatures calculated online by the oceanic component for the Mediterranean Sea and the Black Sea. Prescribed values are employed over the Atlantic.

The hydrological discharge model is a routing scheme developed at the Max Planck Institute for Meteorology by Hagemann and Dümenil (1998). It accounts for the lateral water flow on the land surface in global climate model applications. It is part of the coupled atmosphere-ocean model, providing the ocean component with freshwater input from the surface river system. The model describes the translation and retention of the lateral discharge within the river system as a function of spatially distributed land surface characteristics.

The oceanic component of the coupled model consists in a regional version of the Max Planck Institute Ocean Model (Marsland et al. 2003), which is a primitive equation model. It has a free surface and uses a mass flux boundary condition for salinity. A simple bottom boundary layer scheme is included as well as the standard set of subgrid-scale parameterizations. The horizontal resolution is about $10 \mathrm{~km}$, and 30 levels are used in the vertical. The original global model was modified and limited to the Mediterranean Sea and the Black Sea. The communication with the global ocean is performed by nesting the Mediterranean Sea model in the Atlantic by means of an Atlantic box.

To spin up the ocean in the coupled model, first a 70-yr simulation with the standalone ocean model forced with Ocean Model Intercomparison Project (OMIP) data (Röske 2006) was performed, starting with initial conditions from Levitus observational estimates (Levitus et al. 1998). After this, a 20-yr spinup run of the coupled model was conducted using the final state of the ocean standalone spinup as the initial condition. The coupled spinup run was then taken as starting point of subsequent coupled simulations using reanalysis data as lateral boundary forcing for the atmospheric part of the regional coupled model.

\section{b. Experiments}

All the simulations discussed in this study are performed with limited area models. The model domain is evident from the subsequent figures and agrees with the setup defined in the European Commission's Sixth Framework Programme (FP6) integrated project Climate Change and Impact Research: The Mediterranean Environment (CIRCE). The atmospheric model REMO is forced at the lateral boundary by the 40-yr ECMWF ReAnalysis (ERA-40; Uppala et al. 2005) for the simulation period January 1958 to August 2002 and the Interim ECMWF Re-Analysis (ERA-Interim; Simmons et al. 2007) from September 2002 to December 2003. Accordingly, in the uncoupled, atmosphere-only simulations the sea surface temperatures are taken from the respective reanalysis data. ERA-Interim and ERA-40 agree well in the extratropical troposphere (Dee et al. 2011) and there is no evidence of artificial signals that are caused by differences between the reanalyses in the regional climate model simulations.

For the coupled runs, the Atlantic sea surface temperatures are also prescribed and derived from the reanalysis. Using reanalysis data as forcing has the advantage that the climate model is able to realistically 
TABLE 1. Simulations that were performed for this study.

\begin{tabular}{|c|c|c|}
\hline Acronym & $\begin{array}{l}\text { Time } \\
\text { period }\end{array}$ & Description \\
\hline UNC-HIST & $1958-2003$ & $\begin{array}{l}\text { Uncoupled model, prescribed } \\
\text { historical SSTs }\end{array}$ \\
\hline UNC-CLIMSST & 2003 & $\begin{array}{l}\text { Uncoupled model, climatological } \\
\text { Mediterranean SSTs }\end{array}$ \\
\hline CPL-HIST & $1958-2003$ & $\begin{array}{l}\text { Coupled model, lateral } \\
\text { forcing by reanalysis }\end{array}$ \\
\hline CPL-INICOLD & 2003 & $\begin{array}{l}\text { Coupled model, cold } \\
\text { Mediterranean Sea initialization }\end{array}$ \\
\hline CPL-INIWARM & 2003 & $\begin{array}{l}\text { Coupled model, warm } \\
\text { Mediterranean Sea initialization }\end{array}$ \\
\hline
\end{tabular}

simulate the historic evolution of the climate. Moreover, the fact that the boundary conditions are fixed allows for a controlled experimental setup and a focus on regional climate interactions.

Historical simulations for the period 1958 to 2003 are performed with the uncoupled atmospheric model as well as with the coupled atmosphere-ocean model. For a description of the ocean spinup in the coupled case, see section 2a. In addition, several sensitivity experiments are conducted in order to assess the influence of Mediterranean sea surface temperatures in the uncoupled as well as the coupled simulations. The experiments are summarized in Table 1. In the uncoupled case, a simulation (UNC-CLIMSST) was performed for 2003 with fixed climatological SSTs for the Mediterranean Sea. The SST climatology was derived from the reanalysis for the period 1958 to 2000 . To mimic this setup in the situation of the coupled model, two runs are performed with different Mediterranean Sea initial conditions. Both runs are initialized in January 2003. One simulation is initialized with a relatively cold state of the Mediterranean Sea taken from 1 January 1983 of the historical coupled simulation (CPL-INICOLD), and the other run is initialized with a relatively warm state of the Mediterranean Sea taken from 1 January 1990 of the historical coupled simulation (CPL-INIWARM).

\section{Observations and modeling of summer 2003}

Pressure anomalies in summer 2003 were equivalent barotropic in nature. In June high pressure was located over central Europe and an intensification of the Iceland low can be observed. It was situated west of the United Kingdom in June and July and further southwest in August (Black et al. 2004). July shows persistent temperature anomalies; the pressure distribution was rather slack over central Europe, associated with weak synoptic forcing, with a still somewhat strengthened low over the northern Atlantic and a weak high pressure anomaly over the Mediterranean Sea. In August an amplification by Rossby waves reinforced the preexisting anticyclone over Europe (Grazzini et al. 2003) and resulted in a blocking-like situation. A weak low pressure anomaly over northeastern Europe favored the transport of moist air toward the east of the continent. The regional climate models, both coupled and uncoupled, represent these large-scale features of the geopotential height fields well when driven by reanalysis data at their lateral boundaries (not shown).

The synoptic conditions are reflected in the anomalies for temperature and precipitation (Fig. 2). For observed daily mean temperature and precipitation, version 4 of the data compiled by Haylock et al. (2008) is used in the following. For evaporation observational estimates are taken from objectively analyzed air-sea fluxes (OAFlux) data ( $\mathrm{Yu}$ et al. 2008) in a $1^{\circ}$ resolution. Anomalies are calculated with respect to the reference period 1958 to 2000. In June central Europe experienced strong positive temperature anomalies, while colder air was advected to the northeastern parts of the continent. In July positive anomalies covered most of western Europe with the exception of Portugal. The strongest anomalies occur around the Mediterranean basin and in northern Scandinavia. In August the positive temperature anomalies again dominated over central Europe including Italy.

As a consequence of the stable atmospheric conditions, precipitation anomalies in summer 2003 were mostly negative. In June central and eastern Europe received less than average precipitation, with the exception of northwestern France and Greece. In July the rainfall anomaly signal is weaker. On the western coasts of France and the Iberian Peninsula the rainfall anomaly is slightly positive. This is associated with the Atlantic low pressure center described above. Dry conditions prevail mainly in southern France and Italy, and to a somewhat larger extent in Scandinavia and northeastern Europe, the center of the high pressure system. The anomaly pattern in August again resembles the situation in June, although in August the negative anomaly does not affect the Iberian Peninsula and is stronger over the British Islands. In the northeast of the continent the low pressure anomaly causes above average precipitation.

In the following we focus on differences between the regional coupled model and the uncoupled atmospheric model, which uses prescribed sea surface temperatures from ERA-40 (Uppala et al. 2005) and ERA-Interim (Simmons et al. 2007; Dee et al. 2011). These sea surface temperatures are based on observations, so the uncoupled model is expected to perform better in principle. However, it cannot be excluded that model biases in 
June
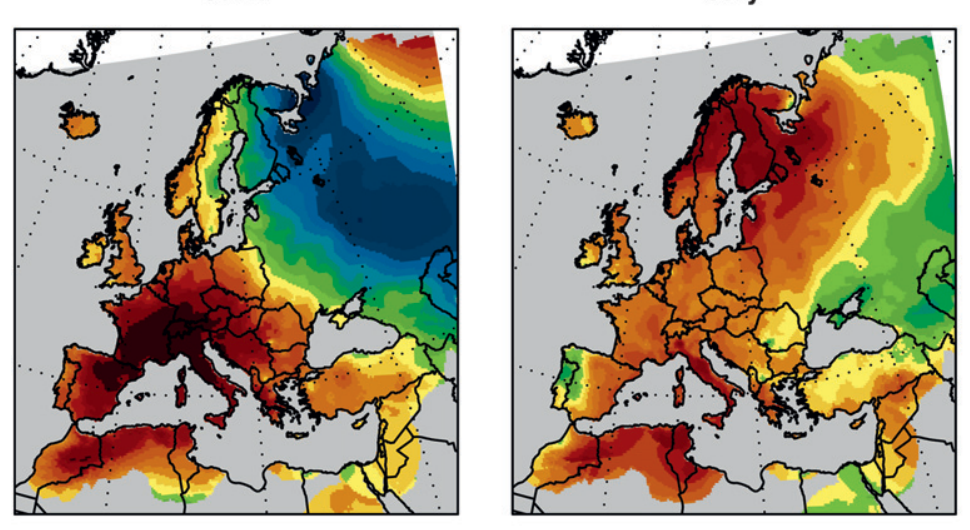

July
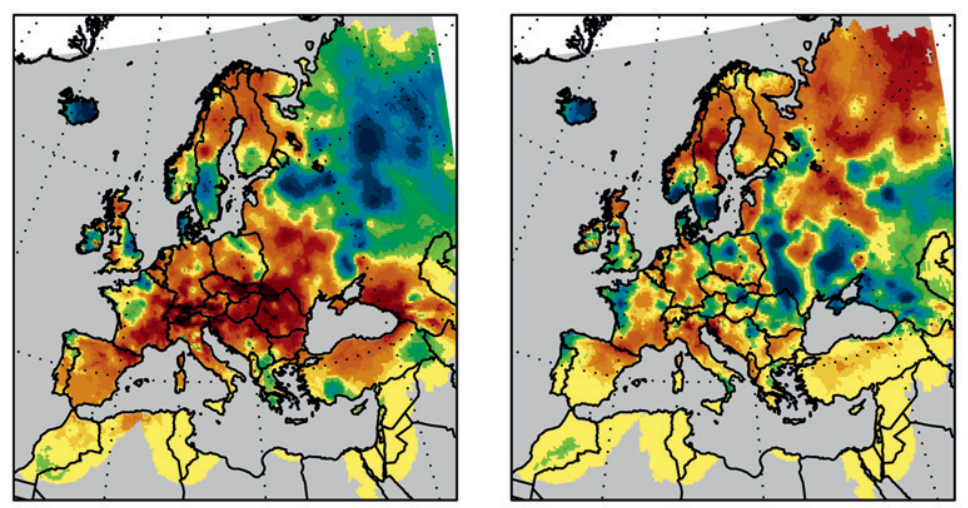

August

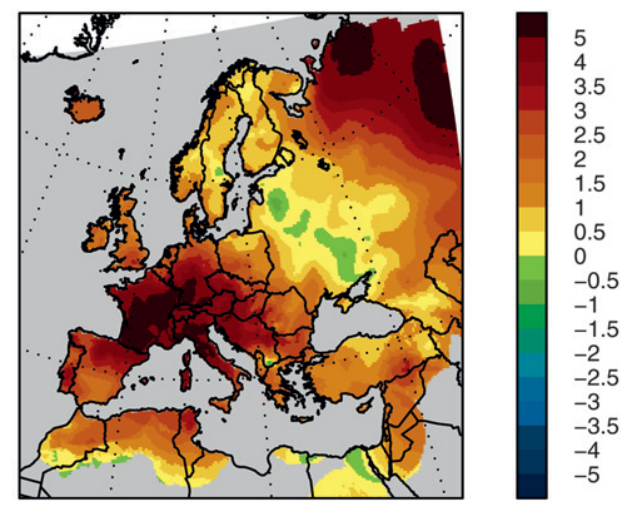

$\left[{ }^{\circ} \mathrm{C}\right]$
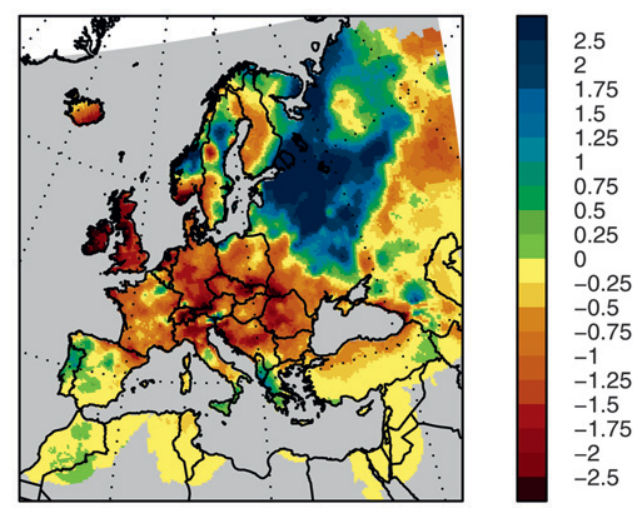

$[\mathrm{mm}]$

FIG. 2. Observed anomalies for 2-m (top) temperature and (bottom) precipitation in summer 2003 compared to the period 1958-2000.

the atmospheric part of the model affect the uncoupled simulation and lead to biased atmosphere-ocean fluxes. Similarly, ocean-atmosphere feedbacks that are free to be active in the coupled simulation may have a favorable impact on the simulation of these fluxes. In the present investigation we are not so much concerned with the mean state of the models, which can be adjusted by tuning to a certain degree, but rather we are most interested in interactions between atmosphere and ocean in the presence of strong atmospheric and oceanic anomalies like those observed during summer 2003.

The following three figures, Figs. 3-5, are structured the same way and show a comparison of the simulations, all driven by reanalysis at the lateral boundaries of the atmospheric part of the model, with observations of 2-m temperature, precipitation, and evaporation for the three months June, July, and August. More precisely, in the first row of the figures the difference between the mean state of the coupled model minus the uncoupled model over the ERA-40 period of the years 1958 to 2000 is displayed. The second row contains the differences between the coupled and the uncoupled model in the simulation of the summer 2003 anomaly. The anomalies are computed with regard to the respective climatological mean state calculated from the years 1958 to 2000. The third row shows the difference of these anomalies and the respective anomalies as reported by the observations in the case of the uncoupled model, and the same for the case of the coupled model in the fourth row.

It is not obvious how to define a measure of significance in these various comparisons. The uncoupled atmospheric regional model is essentially determined by its lateral and surface boundary conditions. There is no internal variability of the model that could be used to define a notion of significance. In the case of the coupled model, different initial conditions generate a certain spread in the simulations. We therefore performed an ensemble of three coupled simulations that are initialized with different, randomly chosen states on 1 January of the year 2000. These three coupled model runs give rise to three different realizations of simulated summer 2003 anomalies. Based on these simulations, together 

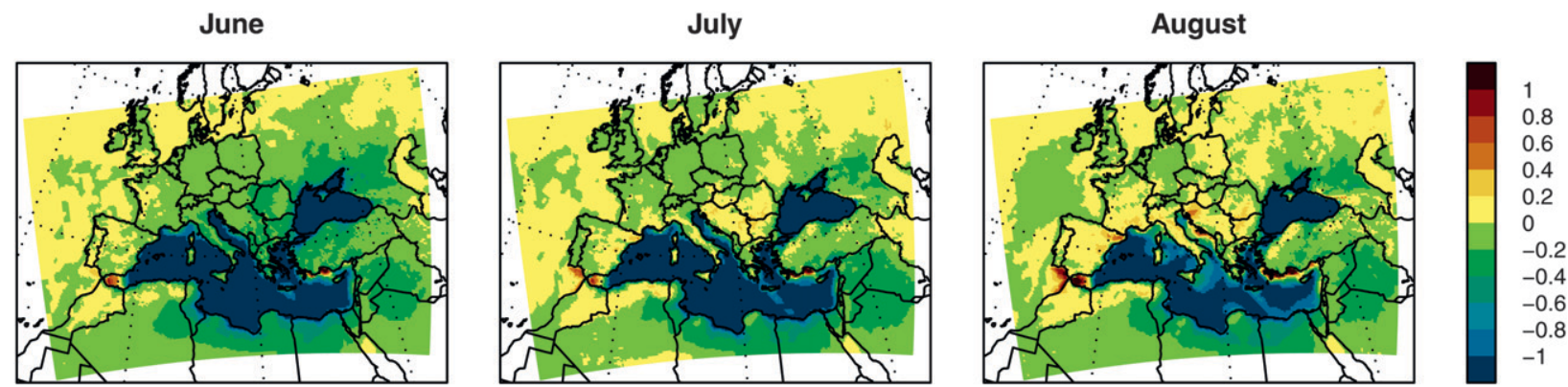

$\left[{ }^{\circ} \mathrm{C}\right]$
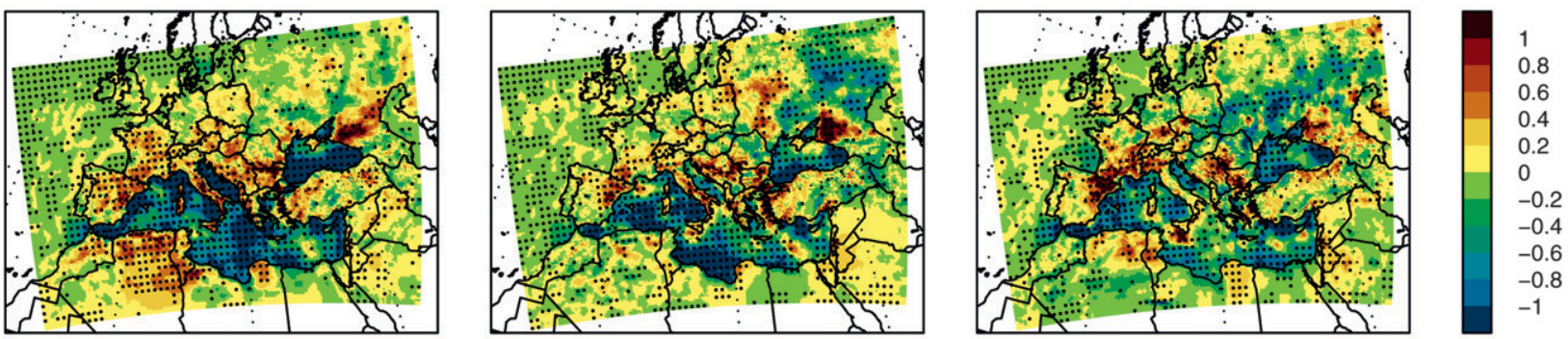

$\left[{ }^{\circ} \mathrm{C}\right]$
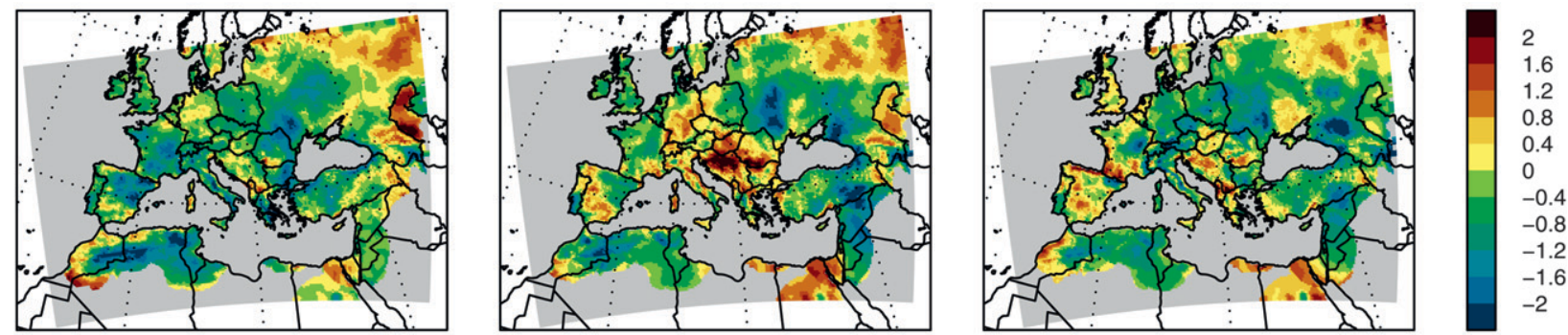

$\left[{ }^{\circ} \mathrm{C}\right]$
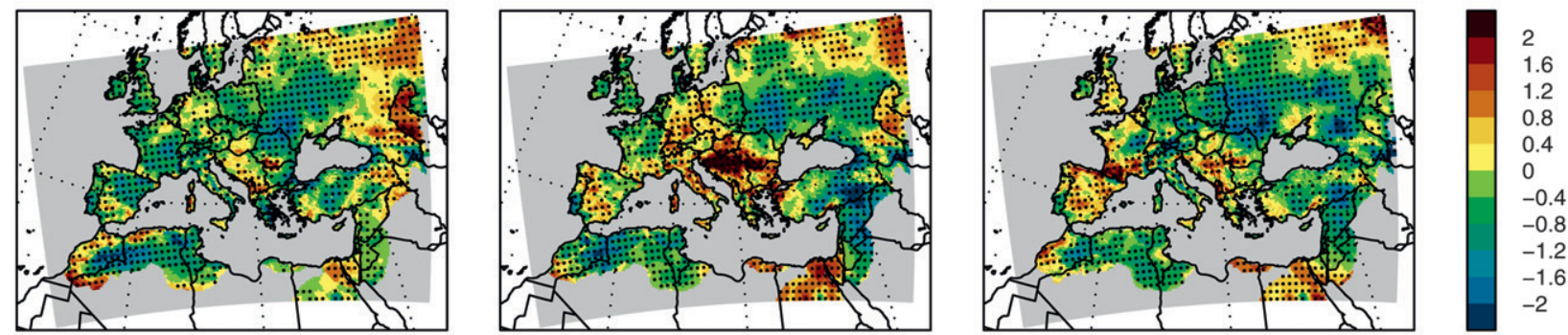

$\left[{ }^{\circ} \mathrm{C}\right]$

FIG. 3. (top) Difference between the mean surface temperature of the coupled model minus the uncoupled model over the years 1958-2000. (second row) Differences between the coupled and the uncoupled model in the summer 2003 surface temperature anomalies. (third row) Difference of the surface temperature anomalies and the respective anomalies as reported by the observations in the case of the uncoupled model. (bottom) Difference of the surface temperature anomalies and the respective anomalies as reported by the observations in the case of the coupled model. 
June

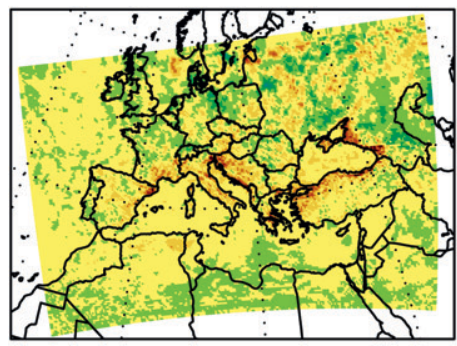

July

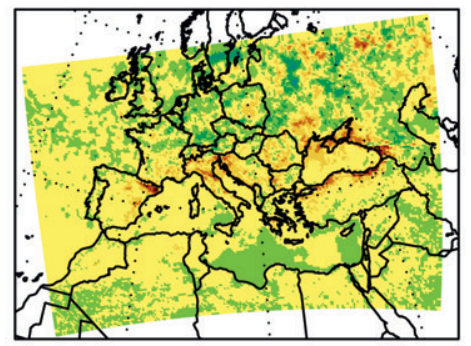

August
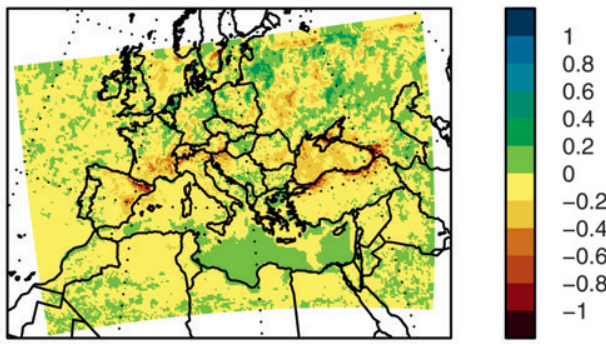

$[\mathrm{mm}]$
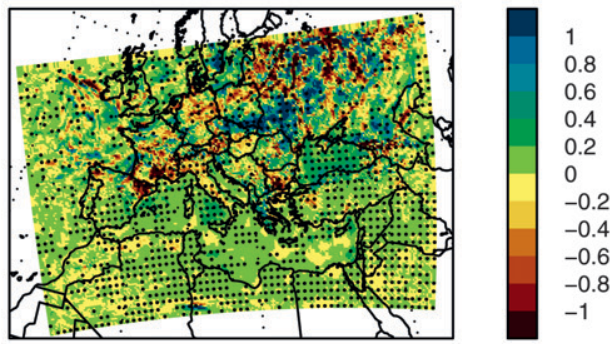

$[\mathrm{mm}]$
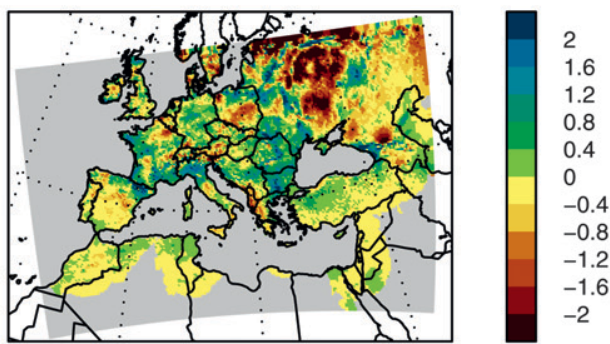

$[\mathrm{mm}]$
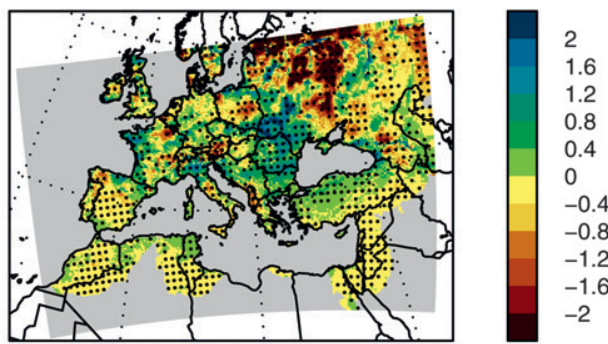

[mm]

FIG. 4. (top) Difference between the mean precipitation of the coupled model minus the uncoupled model over the years 1958-2000. (second row) Differences between the coupled and the uncoupled model in the summer 2003 precipitation anomalies. (third row) Difference of the precipitation anomalies and the respective anomalies as reported by the observations in the case of the uncoupled model. (bottom) Difference of the precipitation anomalies and the respective anomalies as reported by the observations in the case of the coupled model. 

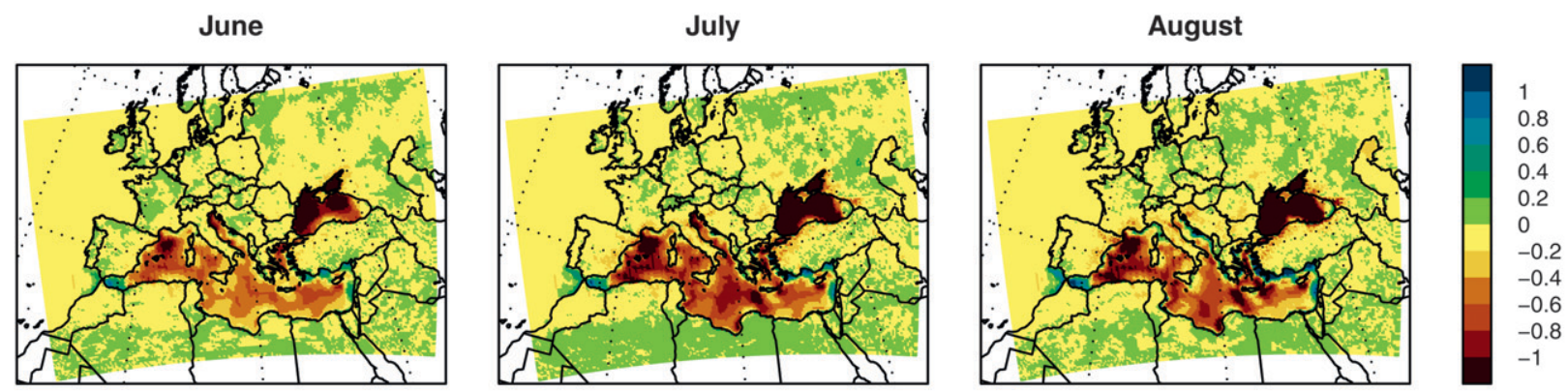

[mm]
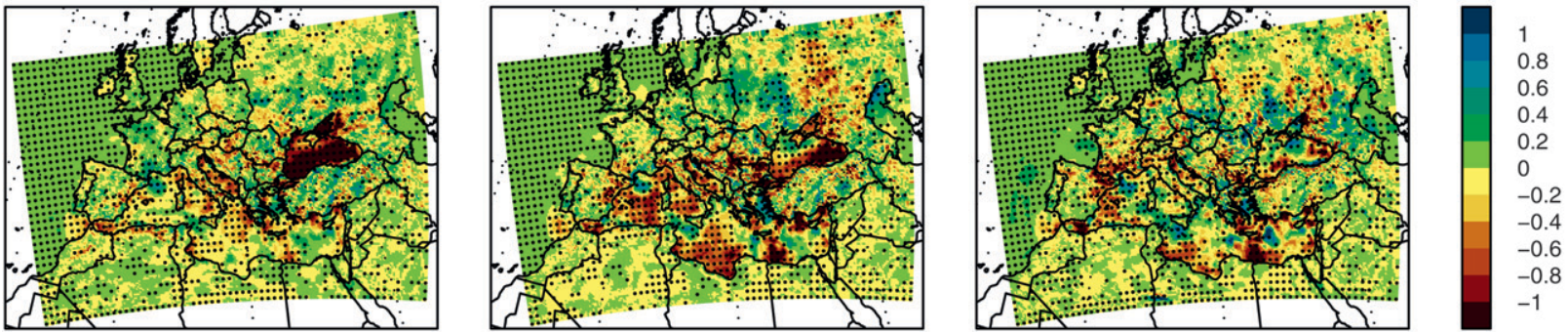

[mm]
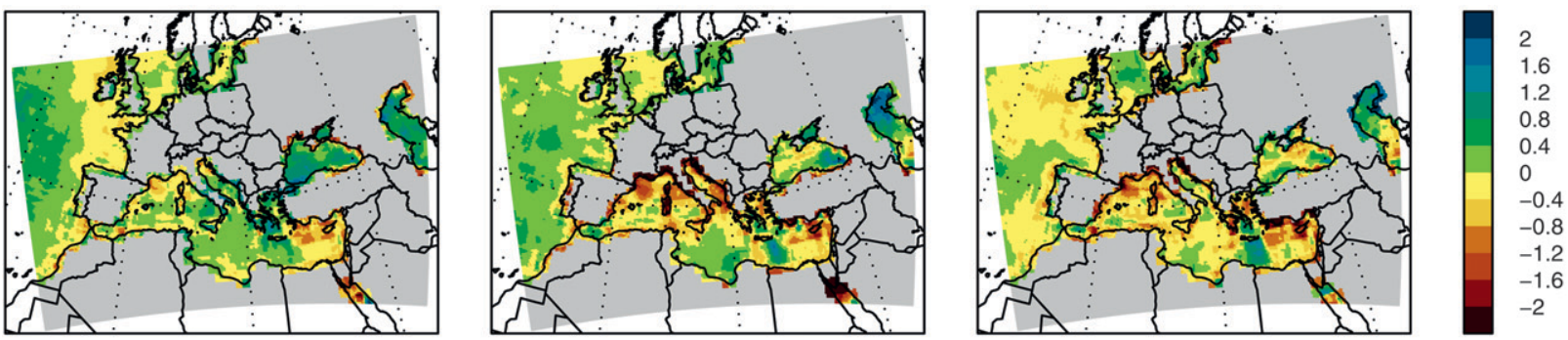

[mm]
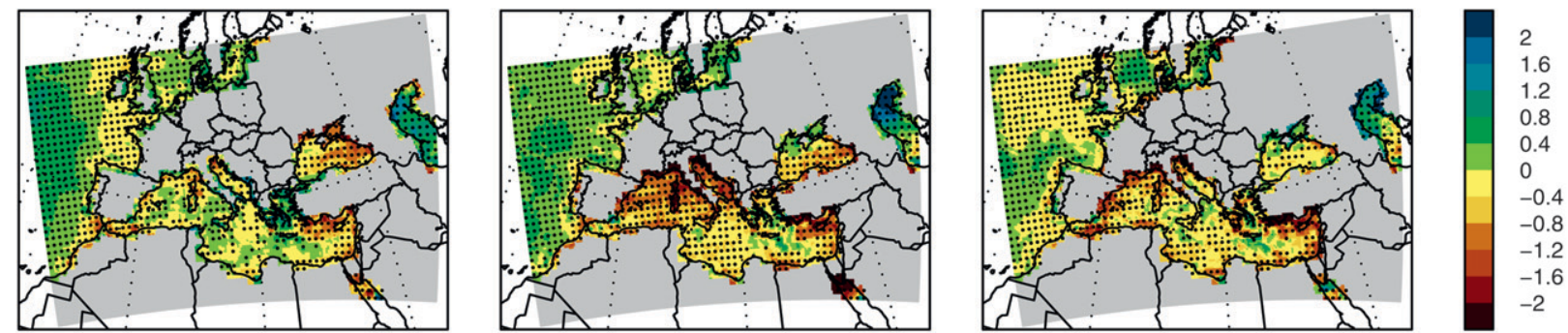

[mm]

FIG. 5. (top) Difference between the mean evaporation of the coupled model minus the uncoupled model over the years 1958-2000. (second row) Differences between the coupled and the uncoupled model in the summer 2003 evaporation anomalies. (third row) Difference of the evaporation anomalies and the respective anomalies as reported by the observations in the case of the uncoupled model. (bottom) Difference of the evaporation anomalies and the respective anomalies as reported by the observations in the case of the coupled model. 
with the original coupled run CPL-HIST, we compute a standard deviation for the various quantities. The black dots in Figs. 3-5 indicate where the differences exceed two standard deviations of the internal variability of the coupled regional model.

In the climatological mean, the Mediterranean sea surface temperatures are colder in the coupled model than the uncoupled model with the prescribed observed sea surface temperatures (Fig. 3, first row). This leads to reduced evaporation over the Mediterranean Sea (Fig. 5 , first row). Over land there is no distinct difference. Also, for precipitation the difference is small with very slightly reduced precipitation in some coastal areas in the coupled model in accordance with the reduced Mediterranean Sea evaporation (Fig. 4, first row).

In the simulation of the summer 2003 the coupled model shows a less pronounced temperature anomaly over the Mediterranean Sea compared to the uncoupled model, but the anomaly over land tends to be larger in many areas of the Mediterranean basin (Fig. 3, second row). Strikingly, this feature is not clearly reflected in the evaporation anomaly over the water (Fig. 5, second row). Over land, the evaporation anomaly tends to become smaller in the coupled model compared to the uncoupled model during the course of the summer. This is due to the fact that the drying of the soil is more pronounced in some areas in the coupled model. The reduced moisture availability due to the reduced evaporation over the Mediterranean Sea may explain this behavior. The soil moisture feedback in turn leads to the larger amplitude in warming over some land regions. Over the Black Sea the coupled model shows better agreement with observed evaporation anomalies. This fact is difficult to interpret and may be due to cancelling errors in the coupled model. Because of the coarser grid cells of the OAFlux observations compared to the finer model grids, interpolation errors occur, most pronouncedly along the coast lines.

The reason for the smaller summer 2003 sea surface temperature anomaly in the coupled model is most probably a consequence of a too small anomaly in incoming shortwave radiation at the surface. Since mixing processes are weak in the Mediterranean Sea during summer, it is unlikely that the causes are related to ocean properties. It would be possible to adjust the mean state of the sea surface temperatures by increasing or decreasing the penetration depth of the incoming radiation into the ocean in the coupled model, but this would have essentially no effect on the anomalies. In the present study we are mainly interested in the anomalies that were observed during summer 2003. Moreover, for the sensitivity studies in section 4 we compare only across different simulations with the coupled regional model. Therefore the described bias in Mediterranean sea surface temperatures in the coupled model does not affect our results.

With regard to precipitation the differences between the coupled and the uncoupled run do not form a particularly systematic picture (Fig. 4). Both simulations reproduce the rainfall deficit in the Mediterranean region during summer 2003. Also, specific features such as the slight positive anomalies in northwestern France in July agree with the observations.

There are hardly any differences in simulated sea level pressure anomalies between the coupled and the uncoupled model (not shown). This suggests that differences are caused mainly by distinct thermal and moisture-related properties and not by differences in the atmospheric circulation.

In summary we can conclude that overall the simulated summer 2003 anomalies by both model configurations agree well with observations (third and fourth rows of the figures). Even details such as the slight negative temperature anomaly over Portugal in July are reproduced. Also the coupled model shows a good performance although the Mediterranean sea surface temperatures are not constrained by observations but are free to evolve in that case. In June the coupled model even shows some slight improvements in the simulation of temperature and evaporation anomalies compared to the uncoupled case, but this could be a consequence of cancelling errors. Nevertheless, a more consistent representation of atmosphere-ocean feedbacks in the coupled simulation might play a role as well.

\section{Results of the sensitivity experiments}

The present study investigates the role of the Mediterranean Sea in affecting the European summer climate. One can differentiate this question into two parts. The first part concerns the sensitivity of the European summer climate to the Mediterranean SSTs without considering feedbacks between the atmosphere and the ocean. Once the influence of the Mediterranean Sea on the European summer climate is established, one can further ask if the Mediterranean Sea is entirely driven by the atmosphere, or whether it plays an active role in impacting climatic conditions during summer over the surrounding continent.

Accordingly, in this section the results of two sensitivity experiments are presented to tackle these two points. The first discusses the effect of different prescribed SSTs in the uncoupled model on the atmospheric state. This allows for quantifying the influence of Mediterranean SSTs on the atmosphere in a controlled way. We focus mainly on possible effects of the SSTs on the 
dynamics of the atmosphere and on the water cycle. The dynamics of the atmosphere is a focus because one could speculate that during summer 2003 the unusually warm SSTs helped to sustain the stable atmospheric conditions and thus acted as a positive feedback. The second suite of experiments investigates the sensitivity of the European summer climate to initial ocean conditions in the coupled regional model. This allows for exploring the precise role of the ocean in the coupled system and for investigating the question of whether the state of the Mediterranean Sea in spring or early summer has a discernible influence on the European climate in summer. The questions about the memory in the Mediterranean surface layers and the role of the feedback of the Mediterranean Sea onto the atmosphere are intimately related. If the internal time scales of the Mediterranean SSTs are of the same order as the time scales of the atmospheric variability, this suggests that the Mediterranean Sea is mainly driven by the atmosphere and that the state of the ocean does not play any distinct role in governing the atmosphere. On the other hand, if the sea surface temperatures are connected to deeper layers of the ocean and exhibit memory that outranges the time scales of the atmosphere, then this implies the potential for the ocean to lead the atmosphere to a certain degree.

\section{a. Uncoupled SST experiment}

In the experiment UNC-CLIMSST (see Table 1) the atmospheric boundary forcing is the one from the year 2003, as derived from the ERA-Interim reanalysis, but the prescribed 6-hourly sea surface temperatures in the domain are defined as climatological means over the period 1958 to 2002 . This simulation is compared to the uncoupled simulation with the observed 2003 sea surface temperatures as lower boundary conditions, called UNC-HIST.

Figure 6 displays the difference between the two experiments for various quantities. Black dots indicate regions where the differences are larger than one standard deviation of the respective seasonal values over the time period 1958 to 2000 in the uncoupled simulation. The surface temperature reflects the strong SST anomaly of summer 2003 in the Mediterranean Sea and parts of the Atlantic Ocean. Over land, however, temperature is reduced in the historical simulation in many parts. The areas of reduced temperature over land match quite consistently with regions of increased evaporation and precipitation, indicating that it is a consequence of evaporative cooling. The rainfall surplus in the run with higher SSTs comes with enhanced evaporation over the ocean and some land areas. This is consistent with a positive signal in vertically integrated water vapor. For vertically integrated cloud liquid water the response is less local (not shown), which indicates that moisture is partly transported away from the Atlantic and Mediterranean area to eastern parts of the continent. The signal in geopotential height is characterized by a surface heat low over the warmer SSTs and slight high pressure ridges over parts of central and eastern Europe. In principle this would support the view that this anomaly reduces the westerly flow and helps to sustain the anticyclonic situation over central Europe, but the amplitude of the signal is weak and not significant at any height level of the atmosphere.

Also, a more detailed investigation of dynamical aspects of the difference between the two simulations does not reveal a significant and consistent pattern. The difference between UNC-HIST and UNC-CLIMSST in vertical wind velocities, for instance, is small in magnitude and mainly restricted to land areas (not shown). The vertical motion of air over Italy is slightly enhanced in the UNC-HIST experiment. The subsidence over eastern land regions is somewhat weakened by the colder SSTs in UNC-CLIMSST at lower levels of the atmosphere, and strengthened at higher altitudes. This could be related to the excess of rainfall and the effectively colder surface temperatures in the UNC-HIST experiment over these areas compared to UNCCLIMSST.

Similarly, atmospheric temperature profiles suggest that the differences in the SSTs induce differences in air temperature mainly near the surface and mostly over the Mediterranean Sea. This feature will attenuate sea breezes during daytime and intensify land breezes at night. But overall there are no indications of discernible differences in the large-scale circulation, in line with the findings by Jung et al. (2006).

The Mediterranean Sea is known to be an important part of the regional water cycle (e.g., Sanchez-Gomez et al. 2011). We therefore examine in the following to what extent the Mediterranean sea surface temperature affects the atmospheric water balance over the neighboring continent. To this end we write the change in the water budget of a column of air as

$$
\frac{d W}{d t}=E(t)-P(t)-\operatorname{Div}(t),
$$

where $W$ denotes the vertically integrated water content, $E$ the surface evaporation, $P$ precipitation, and Div the column integrated divergence of the moisture flux. Positive values of Div imply that the water column at a specific location acts as a moisture source for surrounding regions. In the upper panel of Fig. 7 the vertically integrated divergence of the moisture flux is displayed for the UNC-HIST experiment, while the 


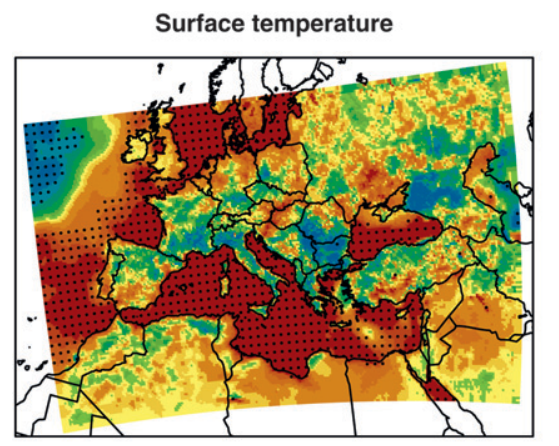

Vertically integrated water vapor

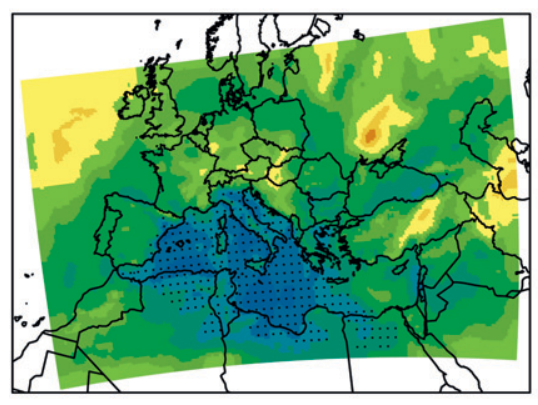

Geopotential height $850 \mathrm{hPa}$

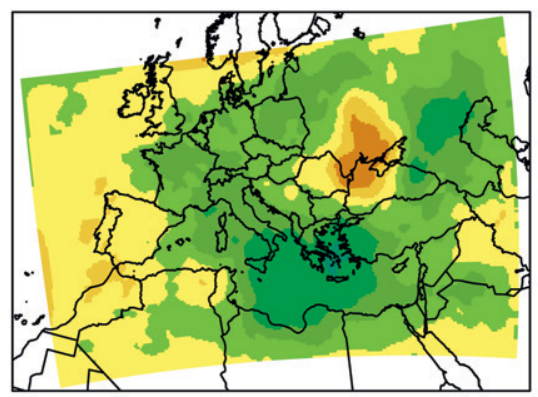

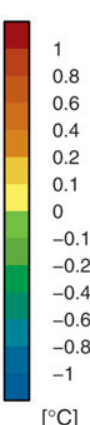

$\left[{ }^{\circ} \mathrm{C}\right]$

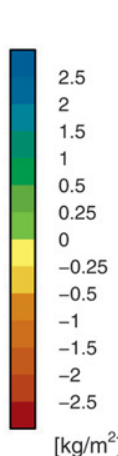

$\left[\mathrm{kg} / \mathrm{m}^{2}\right]$

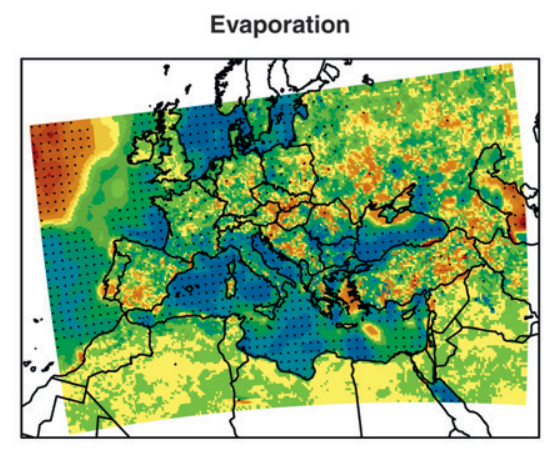

Geopotential height $500 \mathrm{hPa}$

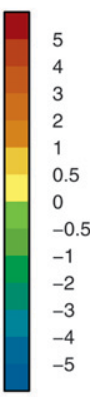

[m]

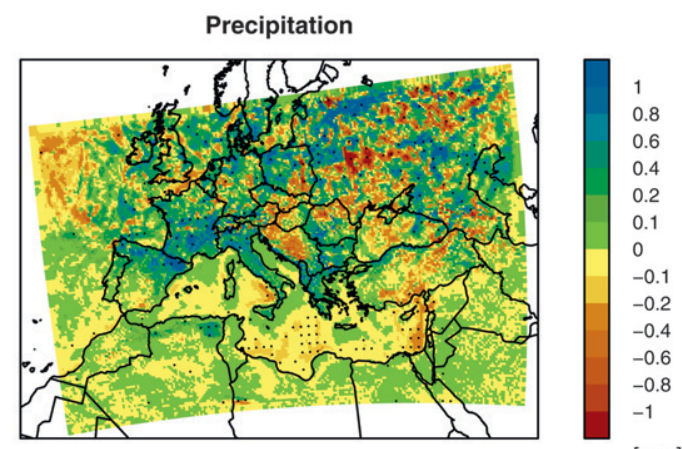

$[\mathrm{mm}]$

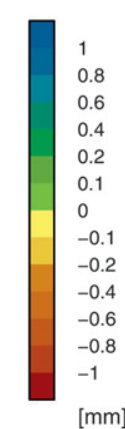

$[\mathrm{mm}]$

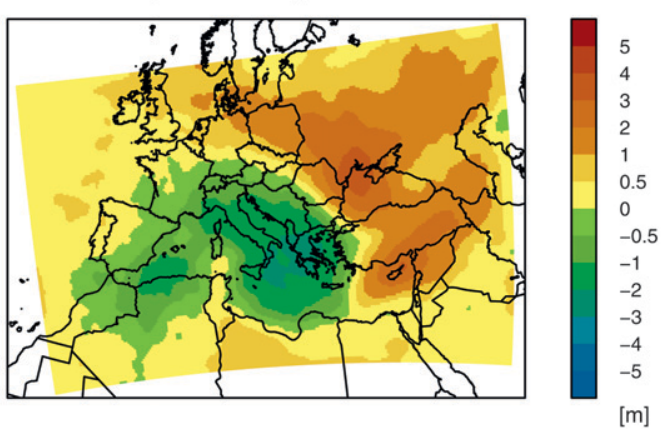

FIG. 6. Difference between the uncoupled historical run and the uncoupled simulation with climatological SSTs for various quantities. Black dots indicate regions where the differences are larger than one standard deviation of the seasonal values over the time period 1958-2000 in the uncoupled simulation.

lower panel shows the difference in moisture flux divergence between UNC-HIST and UNC-CLIMSST. During summer 2003 not only the Mediterranean Sea but also most of western, central, and eastern Europe acted as a source of moisture to the atmosphere, except for the Alps. That is, assuming that the change in the water content of the air column over the whole season is small, evaporation exceeded precipitation in most areas [see Eq. (1)]. The lower panel confirms that evaporation was larger over the Mediterranean Sea and areas of the Atlantic Ocean in the simulation with warmer historical SSTs. This moisture was partly transported to the landmasses. In particular, mountainous regions such as the Alps, the Pyrenees, the Italian Apennines, and the
Greek Pindus mountain range benefit from the moisture excess in the UNC-HIST experiment.

The arrows in the plot indicate the direction and strength of the vertically integrated mean advective moisture transport over the summer 2003. In the mean, moisture is mainly transported from the west to the east in the western part of the continent, and from north to south in the east of the Mediterranean catchment. However, this does not exclude the possibility that for specific rainfall events the source of moisture could come from other directions due to eddy fluxes. Generally, the circulation pattern of moisture is strengthened in the UNC-HIST simulation, indicating that the warmer SSTs intensify the hydrological cycle in the region. 

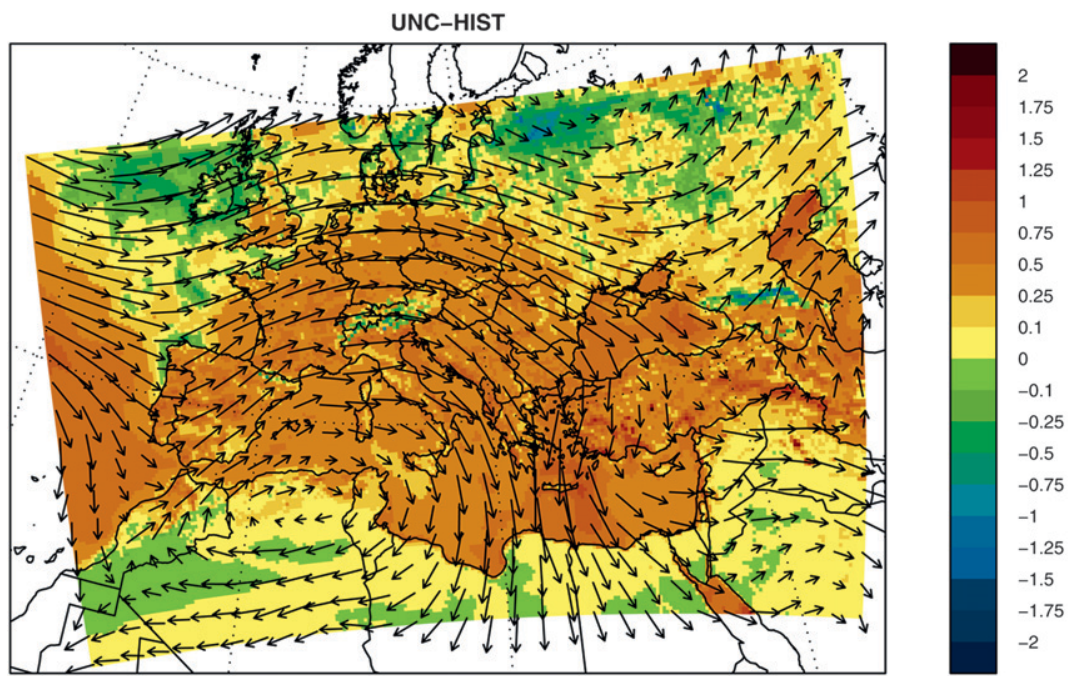

[mm/day]

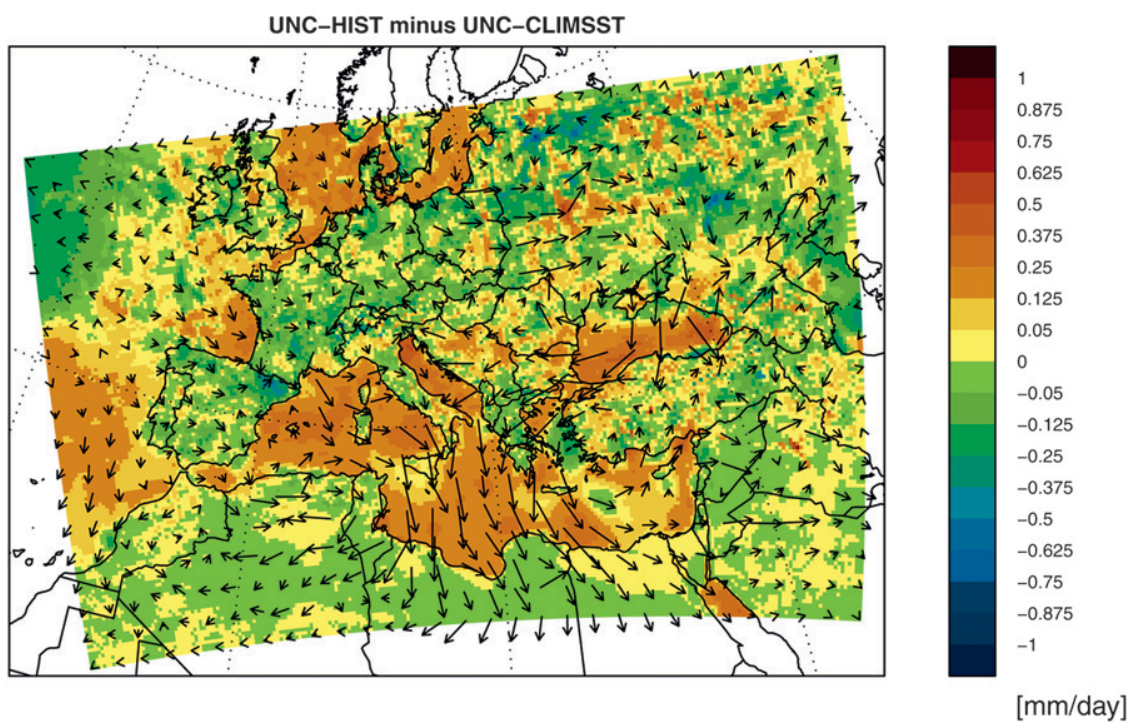

FIG. 7. (top) Color shading indicates moisture divergence in the UNC-HIST experiment. Arrows show the horizontal moisture flux by advection. (bottom) The same quantities as above, but the differences between UNC-HIST and UNC-CLIMSST are shown. In the difference plot arrows are scaled by a factor of 10 .

As already mentioned, the seasonal mean moisture transport does not capture the effect of cyclones that move moisture, in the course of specific rainfall events, in directions that do not coincide with the seasonal mean flow. Therefore we calculated the moisture source for all the rainfall events for specific Mediterranean subcatchments, here called "Southern France," "Adriatic," and "Aegean." The subcatchment boundaries and the results of the analysis are presented in Fig. 8. The method is based on a Lagrangian backtracking algorithm that follows air parcels along their back trajectories. More details about the method can be found in Dirmeyer and
Brubaker (1999). The work of Elizalde and Jacob (2011, manuscript submitted to Climate Dyn.) contains climatological statistics of moisture sources for precipitation in the Mediterranean region.

All three catchments receive more precipitation in the UNC-HIST simulation than in UNC-CLIMSST. The subcatchment Southern France (Fig. 8, top) receives part of the moisture from the Atlantic Ocean, but a substantial contribution comes from the Mediterranean Sea. The third main moisture source is local land evaporation in the subcatchment itself and surrounding areas. The surplus of moisture in UNC-HIST (Fig. 8, top 

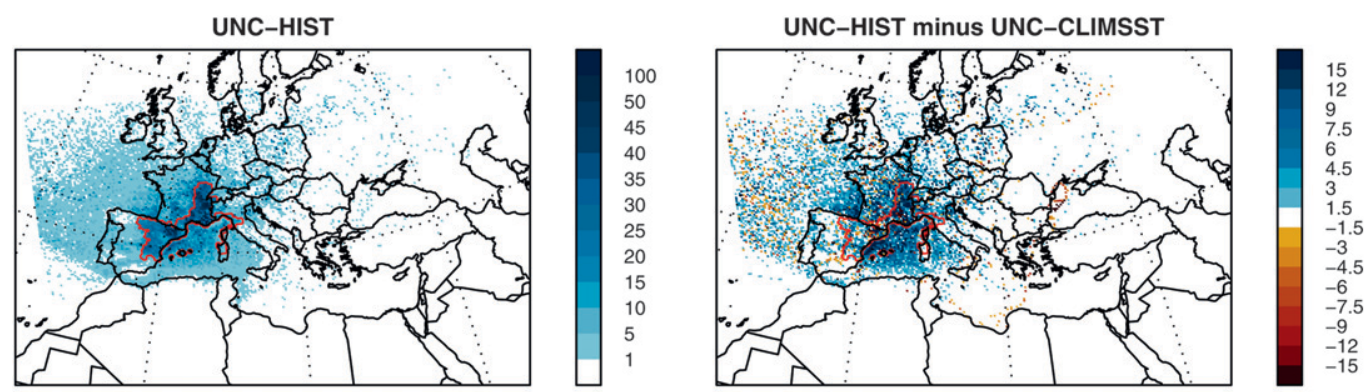

[mm]
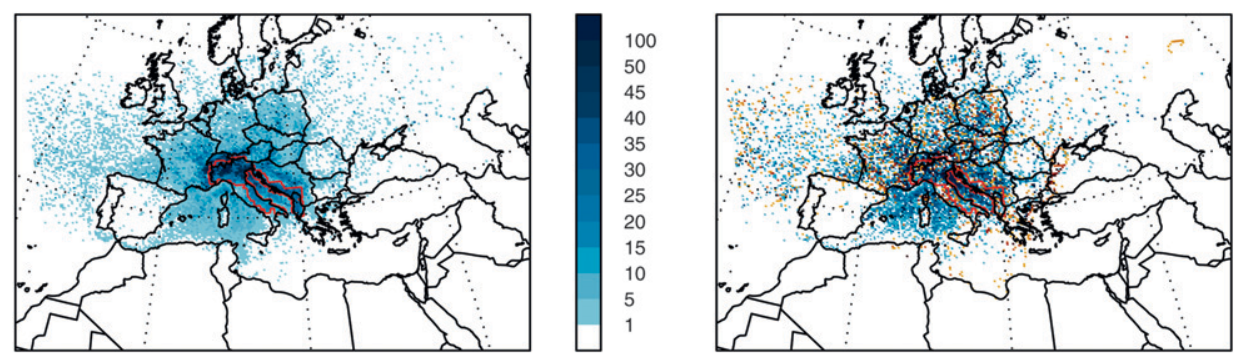

$[\mathrm{mm}]$

$[\mathrm{mm}]$
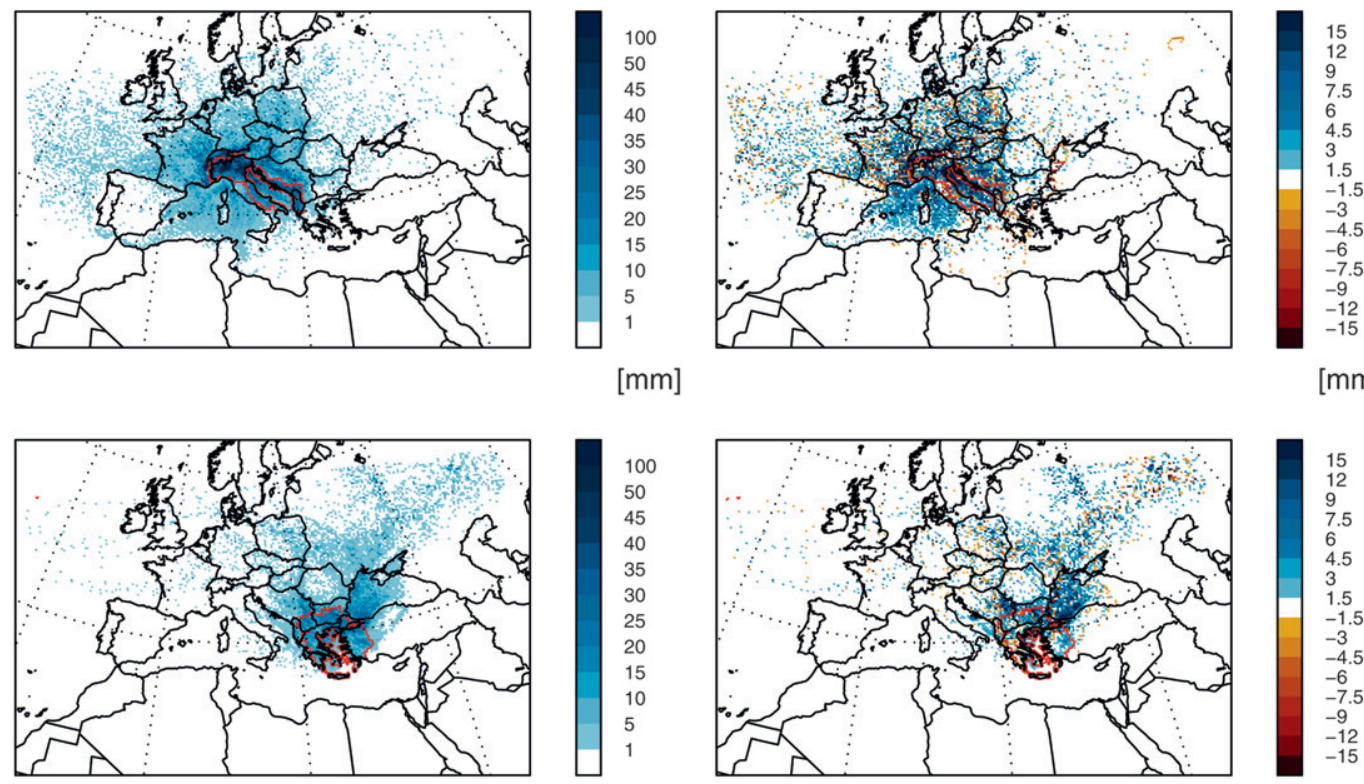

[mm]

FIG. 8. Moisture source for all rainfall events for three Mediterranean subcatchments. (left) Mean over summer 2003 for UNC-HIST. (right) Difference of UNC-HIST and UNC-CLIMSST.

right) stems to a large part from the Mediterranean Sea, but excess evaporation over the Bay of Biscay and land areas in southern France also play a certain role.

The situation is similar for the Adriatic subcatchment (middle row). Here the Mediterranean Sea and especially the Adriatic Sea contribute most to the precipitation increase in UNC-HIST compared to UNC-CLIMSST. In contrast, for the Aegean subcatchment, the excess of moisture can be tracked mostly to the Black Sea and land areas north and northeast of the subcatchment, in accordance with the mean moisture flow.

To assess whether the increase in precipitation of UNC-HIST compared to UNC-CLIMSST is caused by additional precipitation events or simply by increased rainfall intensities, Fig. 9 shows precipitation time series for the three selected subcatchments. Indeed, the rainfall events are mostly more intense in the UNC-HIST simulation. In some cases they last significantly longer, as for instance around 8 August in the Adriatic subcatchment. The enhanced moisture content in the atmosphere strengthens and maintains the formation of precipitation for longer periods of time in some incidents (Lebeaupin et al. 2006).

\section{b. Coupled ocean initial condition experiment}

In the following section we investigate the memory of the Mediterranean Sea and its influence on surrounding land areas. This is the central point in the question of whether the Mediterranean Sea plays an active role in shaping the European summer climate. If the Mediterranean Sea upper ocean temperatures are driven solely by the atmosphere, then this implies that the Mediterranean Sea is a passive component of the system. The Mediterranean Sea may only be an active agent in the regional climate if there is memory in the surface temperatures of the Mediterranean Sea that is rooted in the 
North West

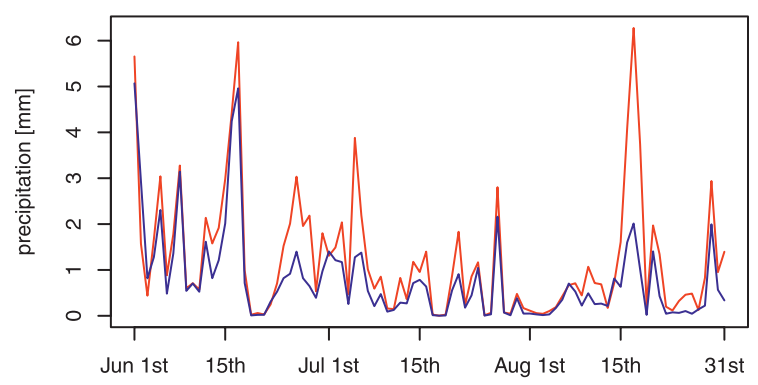

Adriatic

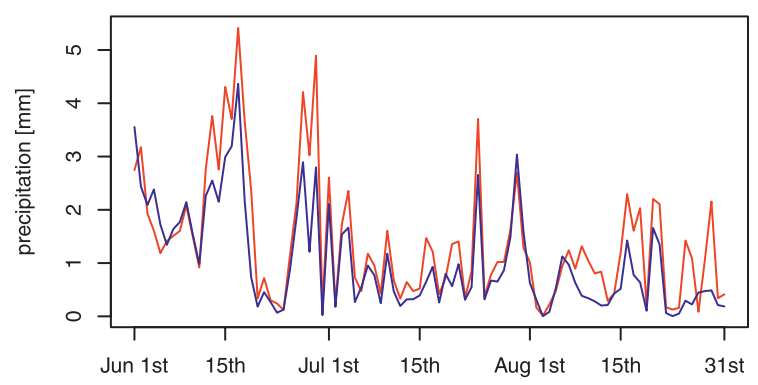

Aegean

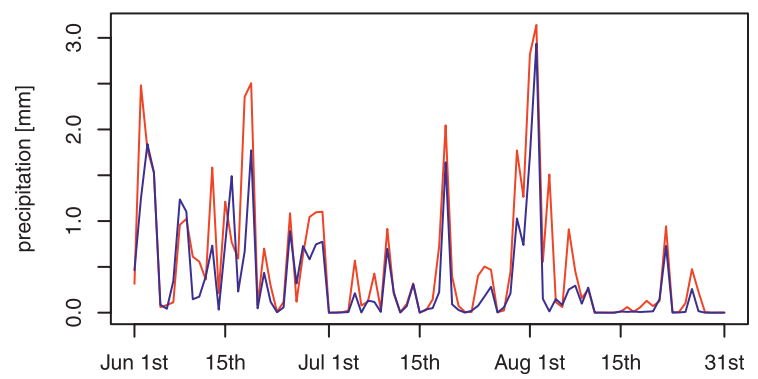

UNC-HIST minus UNC-CLIMSST

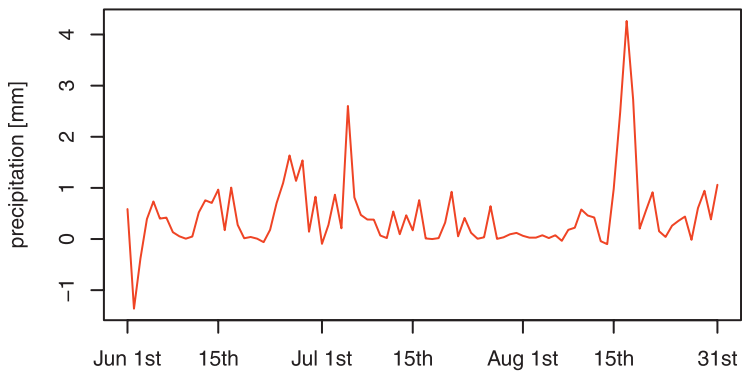

UNC-HIST minus UNC-CLIMSST

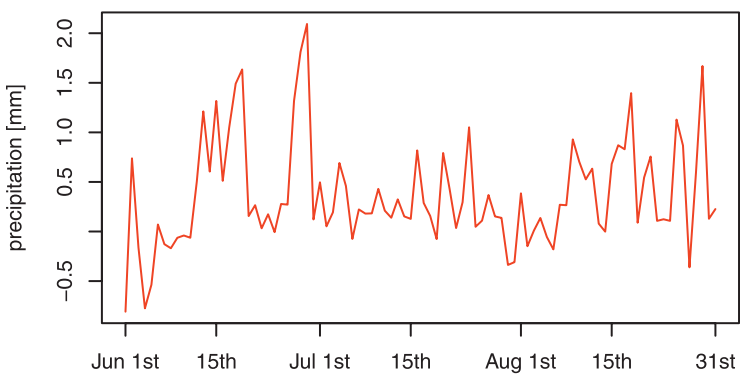

UNC-HIST minus UNC-CLIMSST

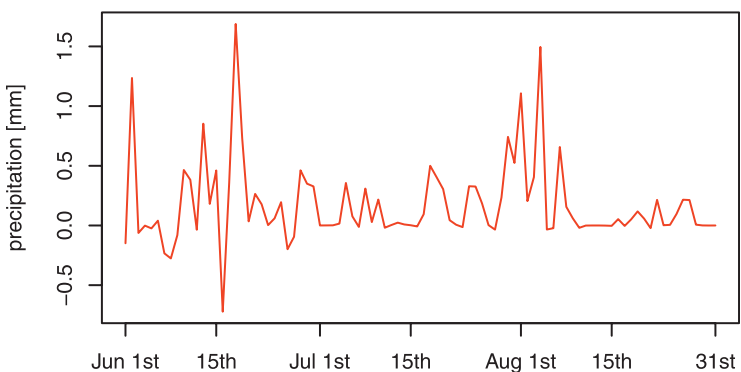

FIG. 9. Precipitation time series for the three selected subcatchments during summer 2003. (left) Absolute values for the UNC-HIST simulation (red) and the UNC-CLIMSST simulation (blue). (right) Difference of the two simulations.

lower levels of the water masses. This key question can only be examined with an ocean-atmosphere coupled climate model.

In the experiment CPL-INICOLD the Mediterranean Sea was initialized on 1 January of the year 2003 in all levels with the state of the Mediterranean Sea of 1 January 11983 of the CPL-HIST simulation. The year 1983 of CPL-HIST was a year with a cold ocean state on 1 January. Analogously, for the experiment CPLINIWARM the Mediterranean Sea was initialized on 1 January of the year 2003 with the state of the Mediterranean Sea of 1 January 1990 of the CPL-HIST simulation. The year 1990 of CPL-HIST was a year with a warm ocean state on 1 January. These two runs are compared with the historical coupled simulation for the year 2003 and the historical coupled simulations of the years
1983 and 1990 in Fig. 10. The upper panel shows the development of the Mediterranean SSTs for 1 January to the end of August, the middle row displays 2-m temperatures averaged over the area of the Mediterranean Sea, and the bottom panel depicts 2-m temperatures averaged over the land part of the total Mediterranean catchment.

To assess the significance of the differences, we use an ensemble of three coupled simulations that are initialized with different randomly chosen states on 1 January of the year 2000. These three coupled model runs give rise to three different realizations of simulated years 2003. Based on these simulations, together with the original coupled run CPL-HIST, we compute a standard deviation for the various quantities. In the following two figures a gray shaded area of two standard deviations is plotted around the line that corresponds to the 


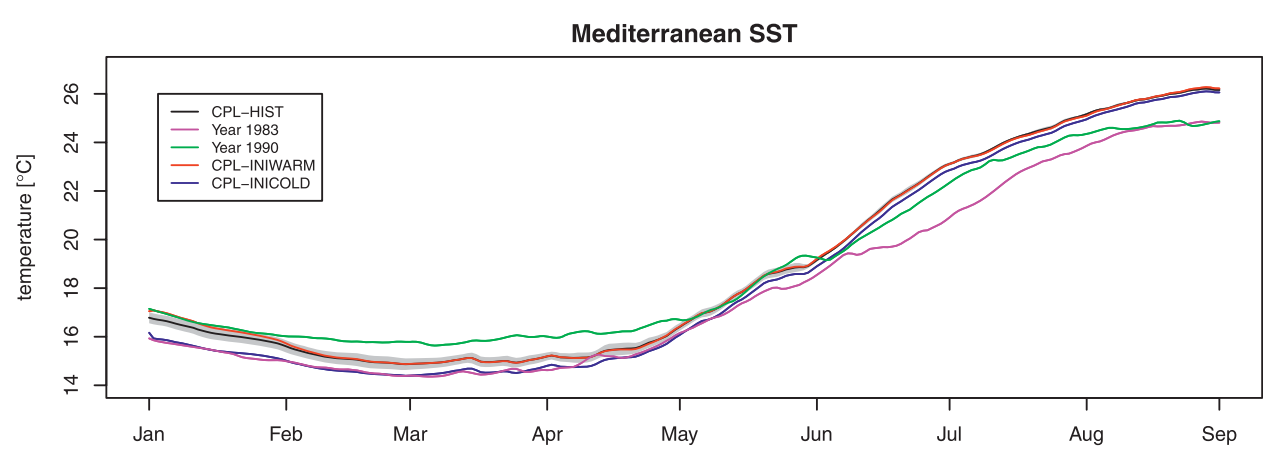

2-meter temperature Mediterranean Sea

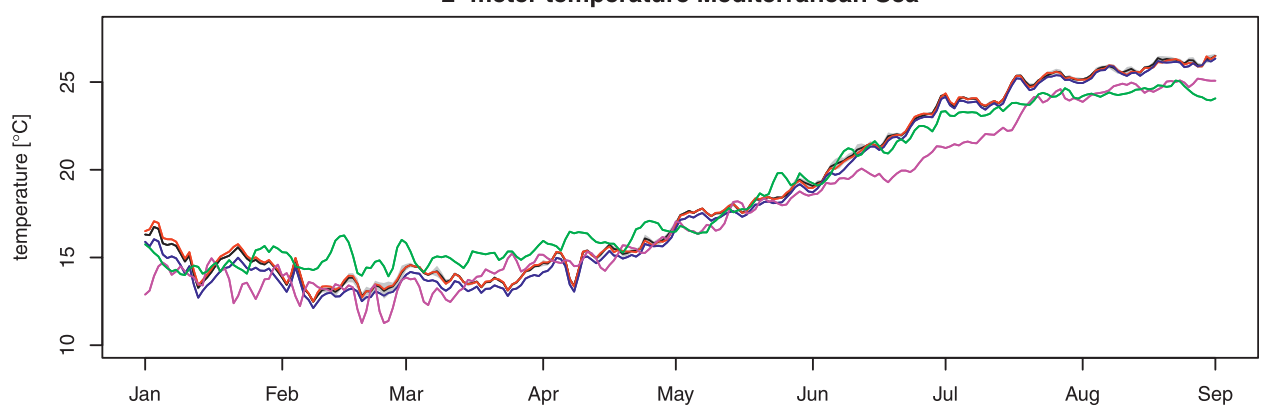

2-meter temperature Mediterranean catchment land

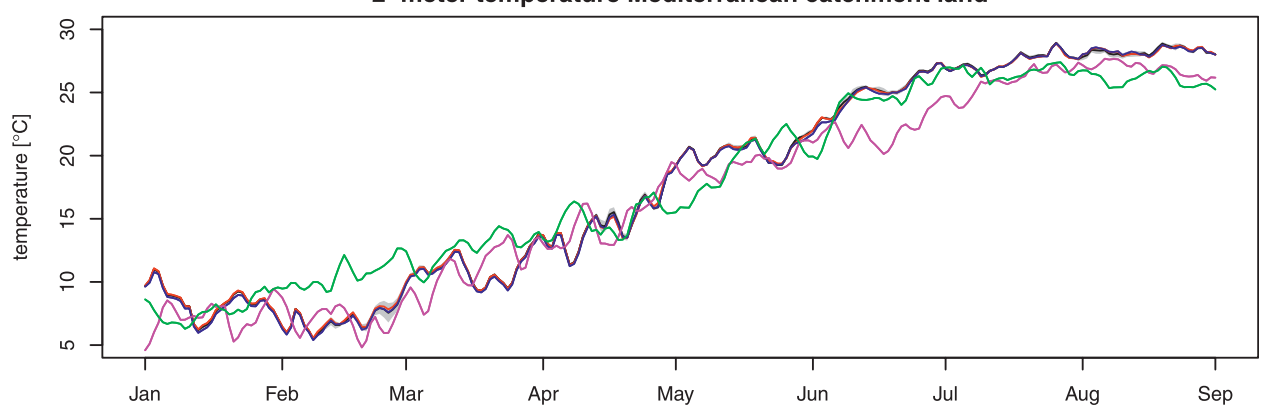

FIG. 10. Daily time series of (top) Mediterranean SST, (middle) 2-m temperature over the Mediterranean Sea, and (bottom) 2-m temperature over the land part of the Mediterranean catchment for the year 2003. Indicated are the experiments CPL-HIST, COL-INICOLD, and CPL-INIWARM as well as the historical years 1983 and 1990.

simulation CPL-HIST. In most of the panels this shaded area is too narrow to distinctly show up, indicating that internal variability originating from different initial conditions is small in the regional coupled model.

Remarkably, Mediterranean SSTs in CPL-INICOLD are substantially different from the SSTs in CPLINIWARM until the beginning of June, although the atmospheric forcing is the same in both experiments. In May, SSTs rise in accordance with atmospheric temperatures for the simulations with the 2003 atmospheric conditions. The comparison with the cold year 1983, which possesses a rather cold atmosphere also in summer, shows that the reaction time of SSTs to atmospheric forcing is much shorter in summer than in winter. Whereas in winter the differences in SSTs between CPL-INICOLD and CPL-INIWARM persist over several months despite the identical atmospheric conditions, the SSTs of CPL-INICOLD and the year 1983 rapidly diverge in summer due to the different atmospheric temperatures. Similarly, in summer the differences in SSTs between the year 1983 and the year 1990 quite closely follow the differences in 2-m temperature over the Mediterranean Sea. However, although the 2-m temperature is almost the same from mid-July, the SSTs only converge in the beginning of August, implying a reaction time of SSTs to atmospheric temperatures of about three weeks.

This suggests that because of the stable stratification of the surface layers of the Mediterranean Sea, the response time of the uppermost levels of the water body is shorter in summer compared to winter. The surface 

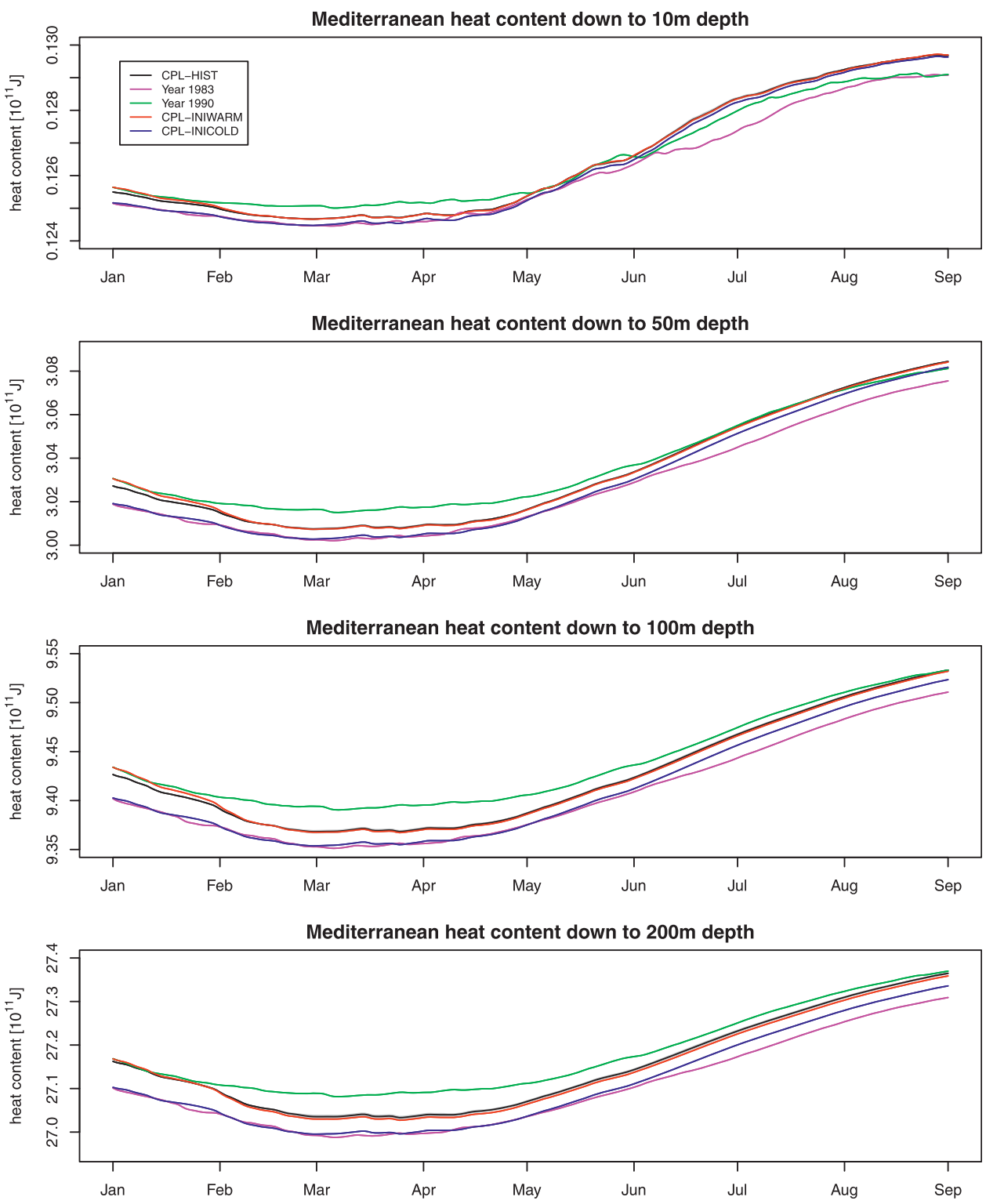

FIG. 11. Daily time series of Mediterranean heat content down to different depths for the year 2003. Indicated are the experiments CPL-HIST, COL-INICOLD, and CPL-INIWARM as well as the historical years 1983 and 1990.

layers are closely connected to the atmosphere in summer. In contrast, because of the weak mixing, lower levels of the ocean do not exert a strong influence on the sea surface temperatures. In winter, however, the upper part of the Mediterranean Sea is less stable and therefore heat is more easily transported across layers. This results in a longer memory of the upper layers of the Mediterranean Sea, which potentially impacts the 2-m temperatures in the region.

This interpretation is supported by time series of the heat content of the Mediterranean Sea down to different depths (Fig. 11). Down to $200 \mathrm{~m}$, and also $100 \mathrm{~m}$, the heat content in CPL-INICOLD is still substantially different from the one in CPL-INIWARM at the end of the summer. Even down to $50 \mathrm{~m}$ one can observe a difference in the heat content at the end of August. At the uppermost levels, however, as indicated by the heat content down to $10 \mathrm{~m}$, the two simulations are very close to each other already during June and hardly distinguishable in August. Similarly, in summer the year 1983 catches up with the year 1990 only in the uppermost layer, which is essentially disconnected from the water below. In contrast, during the winter months, the differences in heat content between CPL-INICOLD 
and CPL-INIWARM are similar in relative terms in all four layers.

\section{Discussion and conclusions}

The present study treats the question whether the Mediterranean Sea plays an active role in shaping the European summer climate. There are two aspects to this issue. In a first step we investigate the impact of Mediterranean SSTs on the European climatic characteristics during summer. However, even if SSTs substantially influence the regional climate, the Mediterranean Sea surface waters could still be driven entirely by the atmospheric conditions. In that case the atmosphere would govern the regional heat and moisture budget. In summer 2003, for instance, the Mediterranean SSTs were anomalously high. In a second step we therefore study if this could actually have been different. Colder Mediterranean SSTs could have been established only if there were memory in the surface layers of the Mediterranean Sea during summer that remembered the state of the ocean in the winter or spring before. While the first question of the influence of Mediterranean SSTs on the climate can be tackled with an atmospheric model and prescribed Mediterranean SSTs, the second, more crucial matter can only be explored using a coupled atmosphere-ocean model.

The experiments are performed with a regional atmosphere and a regional coupled atmosphere-ocean model. The use of regional models is distinguished by the advantage that the summer 2003 is simulated realistically, and that the regional climate features and interactions are well represented due to the high resolution. Although the prescribed lateral boundary forcing defines a constraint on the various simulations, the model domain is chosen large enough that a regional signal originating from ocean surface perturbations can develop and propagate inside the area of interest.

With respect to the sensitivity of the European summer climate to Mediterranean SSTs, our study essentially confirms the conclusions of Jung et al. (2006), which were based on experiments with a global atmospheric circulation model. Warmer SSTs produce a heat low at the surface, evaporation is enhanced, and consequently the moisture content of the atmosphere is increased. The heat low over the water induces a modest high pressure anomaly over parts of the continent, but this signal is weak and restricted to the lowest levels of the atmosphere. Altogether the general circulation is not substantially modified by different Mediterranean SSTs. Although convective activities over landmasses are affected, they are not very consistently altered according to a defined large-scale dynamic response to the change in SSTs. However, in some areas, such as in eastern parts of the Mediterranean basin where subsidence is weakened in the experiment with colder SSTs, a regional signal can be identified.

The main impact of the Mediterranean SSTs on European summer climate becomes evident when analyzing the effect on the moisture balance of the atmosphere. The mean moisture transport is intensified in the simulations with historical anomalously warm SSTs. But also the eddy transport induces enhanced moisture advection and precipitation over land, as shown by the result of the moisture tracking analysis. In general, the excess moisture does not induce additional rainfall events, but precipitation is intensified and in some cases prolonged.

The initial condition experiments with the regional coupled ocean-atmosphere model suggest that in summer 2003 the role of the Mediterranean Sea was essentially passive in nature. At the beginning of 2003 the Mediterranean Sea is indeed relatively warm in our historical coupled simulation, a fact that is not automatically implicit in an experiment where the SSTs are free to evolve. However, the ocean cools in the course of spring and water temperatures become rather low in April. The Mediterranean SSTs then follow quite closely the rising air temperatures in May. Deeper layers of the Mediterranean Sea actually remain colder than average, but because of the strong stratification of the water in summer, heat from the surface is not transported effectively to deeper levels. In winter, when the water column in the Mediterranean Sea is less stable, heat exchange can occur more easily across layers. In that case, mixing processes vertically redistribute energy gained at the surface, which induces a longer memory in the SSTs in winter. In summer, however, the surface water is rather disconnected from deeper layers of the Mediterranean Sea.

One can therefore conclude that although the Mediterranean SSTs were indeed distinctly above average in summer 2003, this was mainly due to the anomalously warm conditions of the atmosphere. It was not an extraordinary state of the Mediterranean Sea that actively enhanced the heat wave over Europe.

Acknowledgments. Very helpful discussions with Jürgen Bader are gratefully acknowledged. Two anonymous reviewers greatly helped to improve the paper.

\section{REFERENCES}

Black, E., and R. Sutton, 2007: The influence of oceanic conditions on the hot European summer of 2003. Climate Dyn., 28, 53-66. 
M. Blackburn, G. Harrison, B. Hoskins, and J. Methven, 2004: Factors contributing to the summer 2003 European heatwave. Weather, 59, 217-223.

Cassou, C., and L. Terray, 2005: Tropical Atlantic influence on European heat waves. J. Climate, 18, 2805-2811.

Dee, D. P., and Coauthors, 2011: The ERA-Interim reanalysis: Configuration and performance of the data assimilation system. Quart. J. Roy. Meteor. Soc., 137, 553-597.

Dirmeyer, P. A., and K. L. Brubaker, 1999: Contrasting evaporative moisture sources during the drought of 1988 and the flood of 1993. J. Geophys. Res., 104 (D16), 19 383-19 397.

Elizalde, A., D. Sein, U. Mikolajewicz, and D. Jacob, 2010: Atmosphere-ocean-hydrology coupled regional climate model. Max Planck Institute for Meteorology Tech. Rep., 5 pp. [Available online at http://www.remo-rcm.de/fileadmin/ user_upload/remo/UBA/pdf/TechnicalReport.pdf.]

Feudale, L., and J. Shukla, 2007: Role of Mediterranean SST in enhancing the European heatwave of summer 2003. Geophys. Res. Lett., 34, L03811, doi:10.1029/2006GL027991.

_ and _ 2011a: Influence of sea surface temperature on the European heat wave of 2003 summer. Part I: An observational study. Climate Dyn., 36, 1691-1703.

— and _ 2011b: Influence of sea surface temperature on the European heat wave of 2003 summer. Part II: A modeling study. Climate Dyn., 36, 1705-1715.

Grazzini, F., and P. Viterbo, 2003: Record-breaking warm sea surface temperature of the Mediterranean Sea. ECMWF Newsletter, No. 98, ECMWF, Reading, United Kingdom, 30-31.

_ , L. Ferranti, F. Lalaurette, and F. Vitart, 2003: The exceptional warm anomalies of summer 2003. ECMWF Newsletter, No. 99, ECMWF, Reading, United Kingdom, 2-8.

Hagemann, S., and L. Dümenil, 1998: A parametrization of the lateral waterflow for the global scale. Climate Dyn., 14, 17-31.

Haylock, M. R., N. Hofstra, A. M. G. Klein Tank, E. J. Klok, P. D. Jones, and M. New, 2008: A European daily high-resolution gridded data set of surface temperature and precipitation for 1950-2006. J. Geophys. Res., 113, D20119, doi:10.1029/ 2008JD010201.
Jacob, D., 2001: A note to the simulation of the annual and interannual variability of the water budget over the Baltic Sea drainage basin. Meteor. Atmos. Phys., 77, 61-73.

Jung, T., F. Ferranti, and A. M. Tompkins, 2006: Response to the summer 2003 Mediterranean SST anomalies over Europe and Africa. J. Climate, 19, 5439-5454.

Lebeaupin, C., V. Ducrocq, and H. Giordani, 2006: Sensitivity of torrential rain events to the sea surface temperature based on high-resolution numerical forecasts. J. Geophys. Res., 111, D12110, doi:10.1029/2005JD006541.

Levitus, S., and Coauthors, 1998: Introduction. Vol. 1, World Ocean Database 1998, NOAA Atlas NESDIS 18, 346 pp.

Marsland, S. J., H. Haak, J. H. Jungclaus, M. Latif, and F. Röske, 2003: The Max Planck Institute global ocean/sea ice model with orthogonal curvilinear coordinates. Ocean Modell., 5, 91-127.

Röske, F., 2006: A global heat and freshwater forcing dataset for ocean models. Ocean Modell., 11, 235-297.

Sanchez-Gomez, E., S. Somot, S. A. Josey, C. Dubois, N. Elguindi, and M. Déqué, 2011: Evaluation of Mediterranean Sea water and heat budgets simulated by an ensemble of high resolution regional climate models. Climate Dyn., 37, 2067-2086.

Simmons, A. J., S. M. Uppala, D. P. Dee, and S. Kobayashi, 2007: ERA-Interim: New ECMWF reanalysis products from 1989 onwards. ECMWF Newsletter, No. 110, ECMWF, Reading, United Kingdom, 25-35.

Uppala, S. M., and Coauthors, 2005: The ERA-40 Re-Analysis. Quart. J. Roy. Meteor. Soc., 131, 2961-3012.

Xoplaki, E., J. F. Gonzalez-Rouco, J. Luterbacher, and H. Wanner, 2003: Mediterranean summer air temperature variability and its connection to the large-scale atmospheric circulation and SSTs. Climate Dyn., 20, 723-739.

Yu, L., X. Jin, and R. A. Weller, 2008: Multidecade global flux datasets from the objectively analyzed air-sea fluxes (OAFlux) project: Latent and sensible heat fluxes, ocean evaporation, and related surface meteorological variables. OAFlux Project Tech. Rep., 64 pp. 